\title{
Specific Binding and Mineralization of Calcified Surfaces by Small Peptides
}

\author{
Daniel K. Yarbrough $\cdot$ Elizabeth Hagerman • Randal Eckert • \\ Jian He $\cdot$ Hyewon Choi $\cdot$ Nga Cao $\cdot$ Karen Le $\cdot$ Jennifer Hedger $\cdot$ \\ Fengxia Qi · Maxwell Anderson • Bruce Rutherford · Ben Wu • \\ Sotiris Tetradis $\cdot$ Wenyuan Shi
}

Received: 4 May 2009/Accepted: 16 October 2009/Published online: 1 December 2009

(C) The Author(s) 2009. This article is published with open access at Springerlink.com

\begin{abstract}
Several small $(<25 \mathrm{aa})$ peptides have been designed based on the sequence of the dentin phosphoprotein, one of the major noncollagenous proteins thought to be involved in the mineralization of the dentin extracellular matrix during tooth development. These peptides, consisting of multiple repeats of the tripeptide aspartate-serine-serine (DSS), bind with high affinity to calcium phosphate compounds and, when immobilized, can recruit calcium phosphate to peptide-derivatized polystyrene beads or to demineralized human dentin surfaces. The affinity of binding to hydroxyapatite surfaces increases with the number of $(\mathrm{DSS})_{\mathrm{n}}$ repeats, and though similar repeated sequences$(\mathrm{NTT})_{\mathrm{n}},(\mathrm{DTT})_{\mathrm{n}},(\mathrm{ETT})_{\mathrm{n}},(\mathrm{NSS})_{\mathrm{n}},(\mathrm{ESS})_{\mathrm{n}},(\mathrm{DAA})_{\mathrm{n}},(\mathrm{ASS})_{\mathrm{n}}$, and (NAA) $n_{n}$-also showed HA binding activity, it was generally not at the same level as the natural sequence. Binding of the (DSS) $)_{\mathrm{n}}$ peptides to sectioned human teeth was shown to be tissue-specific, with high levels of binding to the mantle dentin, lower levels of binding to the circumpulpal dentin, and little or no binding to healthy enamel. Phosphorylation of the
\end{abstract}

D. K. Yarbrough $\cdot$ J. He $\cdot$ H. Choi $\cdot$ N. Cao

K. Le · F. Qi · B. Wu · S. Tetradis · W. Shi $(\bowtie)$

School of Dentistry, University of California,

Los Angeles, CA 90095-1668, USA

e-mail: wenyuan@ucla.edu

E. Hagerman · B. Wu

Department of Bioengineering, University of California,

Los Angeles, CA 90095, USA

R. Eckert · W. Shi

Department of Microbiology, Immunology, and Molecular

Genetics, University of California, Los Angeles,

CA 90095, USA

B. $\mathrm{Wu}$

Department of Materials Science, University of California, Los Angeles, CA 90095, USA serines of these peptides was found to affect the avidity, but not the affinity, of binding. The potential utility of these peptides in the detection of carious lesions, the delivery of therapeutic compounds to mineralized tissues, and the modulation of remineralization is discussed.

Keywords Dentin phosphoprotein · Peptide . Mineralization

The dentin phosphoprotein (DPP) is one of the major noncollagenous proteins found in the dentin extracellular matrix and has long been implicated in the nucleation of hydroxyapatite (HA) during dentin mineralization [1-4]. DPP is found throughout the mineralized dentin in developing teeth [5], and its transcript is expressed in odontoblasts concurrently with the initiation of dentin mineralization $[1,6,7]$. In addition, transient expression of the transcript encoding DPP has been observed in ameloblasts $[6,7]$ as well as in

\author{
B. Rutherford \\ Department of Oral Biology, University of Washington, \\ Seattle, WA 98195, USA \\ Present Address: \\ D. K. Yarbrough - R. Eckert - J. He \\ C3-Jian, Inc, Inglewood, CA 90301, USA \\ J. Hedger $\cdot$ M. Anderson \\ C3-Jian, Inc, Inglewood, CA 90301, USA \\ Present Address: \\ F. Qi \\ College of Dentistry, University of Oklahoma \\ Health Sciences Center, Oklahoma City, \\ OK 73034, USA
}


cementoblasts and osteoblasts [8], suggesting that DPP may be involved in the mineralization of all tooth layers as well as the calcification of bone tissues.

In humans, DPP is the product of the dentin sialophosphoprotein $(D S P P)$ gene, which encodes both DPP and the dentin sialoprotein (DSP) as a single polypeptide, presumed to be proteolytically cleaved into DPP and DSP immediately following translation [9]. While DSP has only modest effects on HA formation, biochemical and genetic studies have shown DPP to have profound effects on both the rate of HA nucleation and the degree of order in the resulting crystals $[9,10]$.

The ability of DPP to affect HA crystal growth and nucleation in vitro has been studied extensively. In subcritical calcium phosphate solutions, immobilized DPP causes marked increases in the rate of HA nucleation, though this effect is not seen with DPP in free solution or with dephosphorylated DPP [11, 12]. In addition, high concentrations of DPP inhibit HA crystal growth [4]. These activities have been attributed to an aspartate- and serine-rich region within the DPP sequence $[2,3,13]$ consisting primarily of a large number of repeats of the sequence Asp-Ser-Ser [9]. This region is known to be highly flexible [14] and highly phosphorylated [3] and is thought to nucleate HA crystal formation by providing an optimal alignment of calcium ion binding sites (or, at high enough concentrations, to cap the surface of existing crystals to prevent further growth).

While some efforts have been made to explore the role of this region in biomineralization, using synthetic peptides consisting of alternating aspartate and phosphoserine residues [3] or short highly phosphorylated peptides derived directly from the DPP sequence [15], we chose to explore the nature of the fundamental repeat unit within DPP, Asp-Ser-Ser (DSS, using the single-letter amino acid symbols), in the absence of serine phosphorylation. Small peptides with varying numbers of DSS repeats have been synthesized, and their roles in the binding and deposition of calcium phosphate have been analyzed. Here, we present evidence that such peptides, ranging in length from six to 24 amino acids, comprising repeats of the sequence (DSS) $)_{n}$ and related short repeats, can bind to calcium phosphates (HA and amorphous calcium phosphate) with remarkably high affinities and further, can bind to mineralized tissues and recruit calcium phosphate to demineralized surfaces without phosphorylation.

\section{Materials and Methods}

Peptide Synthesis

The following peptide sequences were synthesized: 2DSS (DSSDSS), 4DSS (DSSDSSDSSDSS), 6DSS (DSSDS SDSSDSSDSSDSS), 8DSS (DSSDSSDSSDSSDSSDSSDS
SDSS), 4ESS (ESSESSESSESS), 4NSS (NSSNSSNSSN SS), 4DTT (DTTDTTDTTDTT), 4ETT (ETTETTETTETT), 4NTT (NTTNTTNTTNTT), 8DAA (DAADAADAADAADAADAADAADAA), 8NAA (NAANAANAANAA NAANAANAANAA), 8ASS (ASSASSASSASSASSASSASSASS), \#3-1 (LIKHILHRL).

Peptides were synthesized using standard Fmoc solid phase chemistry on an Apex 396 multiple peptide synthesizer (AAPPTec, Louisville, KY) at $0.015 \mathrm{mM}$ scale. Completed peptides were cleaved from the resin with $95 \%$ trifluoroacetic acid and appropriate scavengers. Crude peptide was purified to $90-95 \%$ purity using reverse-phase high-performance liquid chromatography (ACTA Purifier; Amersham, Arlington Heights, IL), and peptide mass was confirmed by matrix-assisted laser desorption/ionization (MALDI) mass spectroscopy. Peptides for use in binding analyses were labeled with 5(6)-carboxyfluorescein prior to cleavage, and peptides for use in assays requiring peptide immobilization were C-terminally labeled with biotin immediately following the cleavage step.

\section{HA Binding Assay}

Fluorescein-labeled DSS-containing peptides of various lengths were subjected to pulldown assays as follows: Samples containing varying concentrations of fluoresceinlabeled peptide $(0-100 \mu \mathrm{M})$ and a fixed amount $(0.3 \mathrm{mg})$ of HA nanocrystals with a specific surface area of $100 \mathrm{~m}^{2} / \mathrm{g}$ (Berkeley Advanced Biomaterials, Berkeley, CA) were prepared. Measurements were taken of the absorbance of the labeled peptide at $488 \mathrm{~nm}$ (the peak absorbance of the fluorescein label) before and after exposure to the HA. The amount of peptide bound was calculated by comparing the ratio of the final $\left(\mathrm{A}_{\mathrm{f}}\right)$ and initial $\left(\mathrm{A}_{\mathrm{i}}\right)$ absorbances to the initial concentration $\left(\mathrm{C}_{0}\right)\left[\mathrm{C}_{\text {bound }}=\left(\mathrm{A}_{\mathrm{f}} / \mathrm{A}_{\mathrm{i}}\right) \mathrm{C}_{0}\right]$. Plots were generated of the amount of peptide bound per meter squared of HA surface area vs. concentration of unbound peptide at equilibrium. The resulting isotherms were fit to the Langmuir isotherm, $\mathrm{x} / \mathrm{m}=\left(\mathrm{K}_{\mathrm{A}} \mathrm{N}_{\max } \mathrm{C}_{\mathrm{eq}}\right) /\left(1+K_{\mathrm{A}} \mathrm{C}_{\mathrm{eq}}\right)$, where $\mathrm{x} / \mathrm{m}$ represents the molar amount of peptide bound per unit of HA surface area, $K_{\mathrm{A}}$ is the affinity constant of the peptide for the HA surface (L/Mol), $N_{\max }$ is the maximum surface concentration $\left(\mathrm{mol} / \mathrm{m}^{2}\right)$, and $\mathrm{C}_{\mathrm{eq}}$ is the molar concentration of unbound peptide at equilibrium [16].

Binding of Calcium Phosphate to Immobilized DSS Peptides

Streptavidin-coated polystyrene beads with an average diameter of $4 \mu \mathrm{m}$ (Spherotech, Lake Forest, IL) were incubated with either biotin-conjugated 8DSS peptide or unconjugated biotin (control beads). Beads were washed with PBS to remove unbound peptide (or unbound biotin in 
control beads) and incubated in a solution of PBS $+1 \mathrm{mM}$ $\mathrm{CaCl}_{2}+1 \mathrm{mM} \mathrm{NaHPO}_{4}$ for 12 days prior to imaging.

\section{Mouse Bone Marrow Culture}

Mouse bone marrow cultures were grown to confluence in DMEM $+10 \%$ FBS and then treated continuously for 3 weeks with either $2.5 \mu \mathrm{M}$ 5(6)-carboxyfluorescein-labeled 6DSS or $2.5 \mu \mathrm{M} 5$ (6)-carboxyfluorescein-labeled peptide \#31 (control peptide) in $\alpha$-MEM $+10 \%$ FBS $+50 \mu \mathrm{g} / \mathrm{mL}$ ascorbic acid $+4 \mathrm{mM} \beta$-glycerophosphate. Cultures were imaged by fluorescence microscopy using a FITC excitation/ emission filter set.

\section{Binding and Mineralization of Tooth Surfaces}

Adult human molars, extracted during normal clinical practice, were sagittally sectioned (Accutom-50, Copenhagen, Denmark; CA-231 diamond blade) and demineralized with $19 \%$ ethylenediaminotetraacetic acid (EDTA) gel for $1 \mathrm{~h}$, followed by immersion in deionized water and ultrasonication to remove debris. Samples were treated with either $12.5 \mu \mathrm{M}$ 8DSS peptide in $50 \mathrm{mM}$ HEPES buffer ( $\mathrm{pH}$ 7.0) or buffer alone (no peptide) or were left untreated for $1 \mathrm{~h}$ prior to remineralization with Quell Desensitizer (Pentron Technologies, Wallingford, CT), a remineralization solution consisting of aqueous solutions of calcium chloride and potassium phosphate, for $15 \mathrm{~min}$. Samples were rinsed thoroughly prior to imaging by scanning electron microscopy.

For binding experiments, sagittally sectioned adult human molars were incubated for $10 \mathrm{~min}$ in a solution of $12.5 \mu \mathrm{M}$ 5(6)-carboxyfluorescein-labeled 6DSS peptide containing $10 \mathrm{mM} \mathrm{NaCl}$ and $50 \mathrm{mM}$ HEPES, pH 7.0. Control samples were prepared without peptide. Samples were rinsed after treatment and imaged by confocal laser scanning microscopy (CLSM) with illumination by a blue $\operatorname{Kr} / \operatorname{Ar}$ laser $(\lambda=488 \mathrm{~nm})$ and a FITC emission filter.

\section{Results}

Quantitative Analysis of DSS-Peptide Binding to HA Surfaces

In order to quantitatively assess the strength of the DSSHA interaction as well as to determine the roles of peptide length and sequence on binding, fluorescein-labeled, DSScontaining peptides of various lengths were subjected to pulldown assays as described in "Materials and Methods."
The experimental data were fit to the Langmuir isotherm, which describes the binding of molecules to surfaces with the conditions that (1) all binding sites have the same affinity for the peptide and (2) the peptide will form a monolayer on the surface but cannot accumulate to higher levels [17]. The excellent fit of the Langmuir isotherm to the experimental data validates these conditions, and the constants obtained from this analysis were used for comparisons between peptides. As shown in Fig. 1a and summarized in Table 1, both the binding affinity $\left(K_{\mathrm{A}}\right)$ and the monolayer concentration $\left(N_{\mathrm{Max}}\right)$ of the various peptides increased with the number of DSS repeats per peptide. Additionally, several variant peptides were tested (Fig. 1b, c, Table 1): a peptide containing a longer side chain at the first position (4ESS), peptides containing a more sterically hindered hydroxyl group at the second and third positions (4DTT, 4NTT, 4ETT), peptides lacking a charged group at the first position (4NSS, 8ASS), and peptides lacking hydroxyl groups at the second and third positions (DAA-8, 8NAA). By comparing the affinities of these variants with those of DSS-containing peptides of the same size, it was determined that elimination of the negatively charged residue (4NSS, 4NTT, Fig. 1b; 8ASS, Fig. 1c) resulted in significant loss of binding affinity, while replacement of the Ser residues with Thr or Ala (4DTT, 4ETT, Fig. 1b; DAA8, Fig. 1c) had little observable effect on this parameter (e.g., DAA-8 has a $K_{\mathrm{A}}$ that is within experimental error of the $K_{\mathrm{A}}$ for 8DSS). Peptides in which both the acidic residue at the first position and the serine residues at positions 2 and 3 were replaced (4NTT, Fig. 1b; 8NAA, Fig. 1c) led to near-total loss of binding activity.

Because binding activity is determined by both the binding affinity $\left(K_{\mathrm{A}}\right)$ and the maximum monolayer concentration $\left(N_{\text {Max }}\right)$, peptides that show similar affinities can vary widely in their overall activity due to differences in $N_{\text {Max }}$. Thus, while the presence of a negative charge at position 1 of the repeat is clearly the key sequence parameter in determining binding affinity, these data suggest that both the acidic residues and the serines are involved in binding of these peptides to HA surfaces: AspSer-Ser is the optimal sequence giving rise to HA-binding activity (due to the effect of the serines on the maximum monolayer concentration), while all of the variant peptides show markedly reduced binding to HA in vitro. Interestingly, phosphorylation of the first position of the DSS repeat-peptide $4 \mathrm{DS}(\mathrm{P}) \mathrm{S}$ - did not lead to a significant change in binding affinity relative to an unphosphorylated peptide of the same size (peptide 4DSS) but rather gave a large increase in the surface binding density, suggesting an alteration in the binding mode rather than simply the affinity of the interaction (Table 1). 

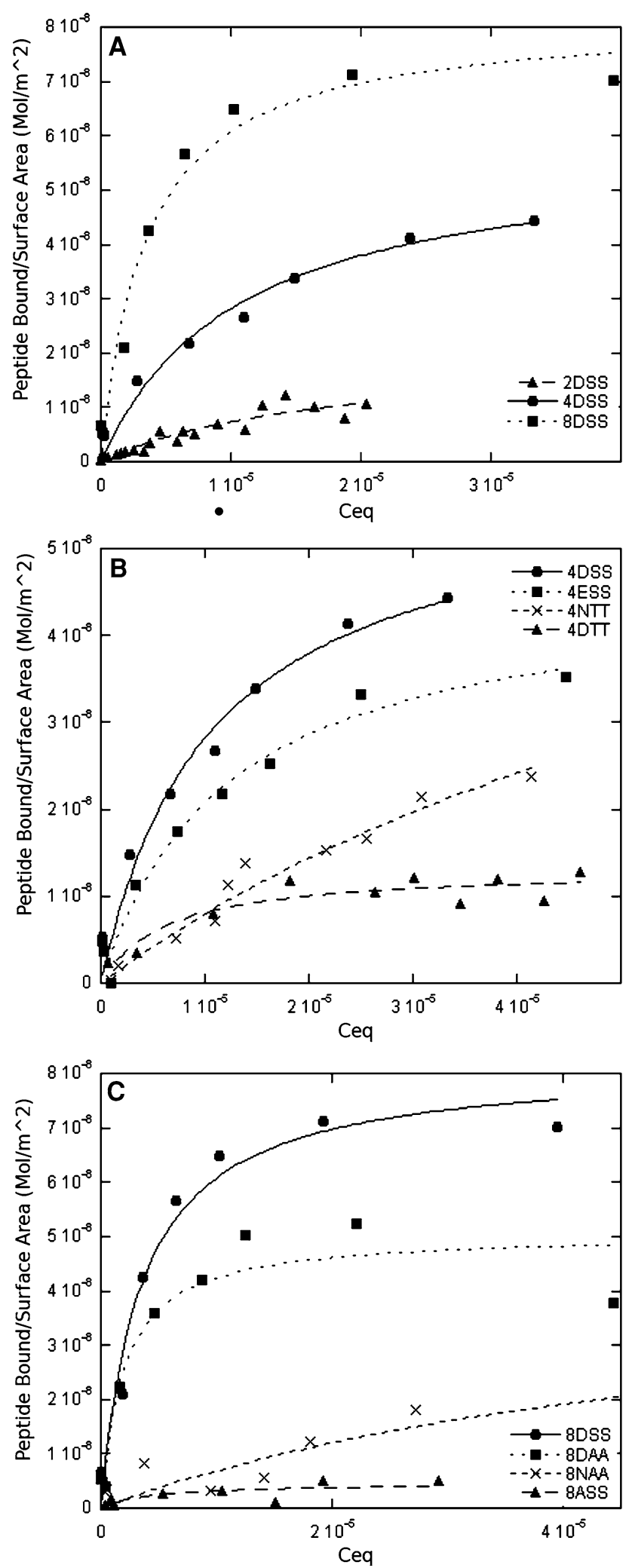

Fig. 1 Equilibrium isotherms for binding of selected (DSS $)_{n}$-containing peptides and variants to HA. a Binding of (DSS) n $^{-}$-containing peptides of various lengths. $\mathbf{b}$, $\mathbf{c}$ binding of sequence variants
Table 1 Langmuir parameters of peptides described in this study, based on fits of the Langmuir equation to raw data

\begin{tabular}{llll}
\hline & $K_{\mathrm{A}}\left(\mathrm{M}^{-1}\right)$ & $N_{\text {max }}\left(\mathrm{mol} / \mathrm{m}^{2}\right)$ & $r$ \\
\hline 2DSS & $57,000 \pm 24,000$ & $2.0 \times 10^{-8} \pm 5 \times 10^{-9}$ & 0.94 \\
4DSS & $94,000 \pm 26,000$ & $5.8 \times 10^{-8} \pm 6 \times 10^{-9}$ & 0.98 \\
5DSS & $148,000 \pm 14,000$ & $9.2 \times 10^{-8} \pm 2 \times 10^{-9}$ & 0.99 \\
6DSS & $272,000 \pm 26,000$ & $1.3 \times 10^{-7} \pm 3 \times 10^{-9}$ & 0.99 \\
8DSS & $290,000 \pm 70,000$ & $8.2 \times 10^{-8} \pm 6 \times 10^{-9}$ & 0.99 \\
4ESS & $81,000 \pm 18,000$ & $4.6 \times 10^{-8} \pm 4 \times 10^{-9}$ & 0.99 \\
4NSS & $16,000 \pm 4,000$ & $3.0 \times 10^{-8} \pm 1 \times 10^{-8}$ & 0.99 \\
4DTT & $161,000 \pm 79,000$ & $1.3 \times 10^{-8} \pm 1 \times 10^{-9}$ & 0.92 \\
4ETT & $79,000 \pm 25,000$ & $8.8 \times 10^{-8} \pm 9 \times 10^{-9}$ & 0.94 \\
4NTT & $17,000 \pm 7,000$ & $5.8 \times 10^{-8} \pm 2 \times 10^{-8}$ & 0.98 \\
8DAA & $310,000 \pm 74,000$ & $6.0 \times 10^{-8} \pm 6 \times 10^{-9}$ & 0.99 \\
8ASS & ND & ND & ND \\
8NAA & ND & ND & ND \\
4DS(P)S & $83,000 \pm 9,000$ & $1.2 \times 10^{-7} \pm 5 \times 10^{-9}$ & 0.99 \\
\hline
\end{tabular}

$N D$ not determined; binding parameters below detection limits for the assay used

Binding of DSS-Containing Cultures to Mineralizing Tissue Cultures

Having established that (DSS) $)_{\mathrm{n}}$-containing peptides are able to actively bind HA, we sought to determine whether they would bind to emerging sites of mineralization in biologically derived tissue. Mouse bone marrow (MBM) cultures, cultured under osteogenic conditions, were treated continuously for 3 weeks with either labeled 6DSS peptide or labeled peptide \#3-1 (non-calcium-binding control peptide). Cultures were imaged by fluorescence microscopy using a FITC excitation/emission filter set. Figure $2 b$ shows bright staining of the mineralizing MBM nodules in the DSStreated sample, with no binding seen in the control sample (Fig. 2d), indicating not only that the labeled 6DSS peptide binds to mineralizing nodules in MBM cultures but also that this binding is a property of the DSS sequence, rather than a general property of small peptides.

\section{Binding of Amorphous Calcium Phosphate} by DSS-Containing Peptides

To test the ability of DSS-containing peptides to recruit calcium phosphate and to nucleate crystal growth, $25 \mu \mathrm{M}$ 6DSS peptide was combined with varying concentrations of $\mathrm{CaCl}_{2}$ and $\mathrm{NaHPO}_{4}$ and incubated as described in "Materials and Methods." Though it was expected that the presence of the free DSS-containing peptide would enhance the formation of HA crystals at subcritical 

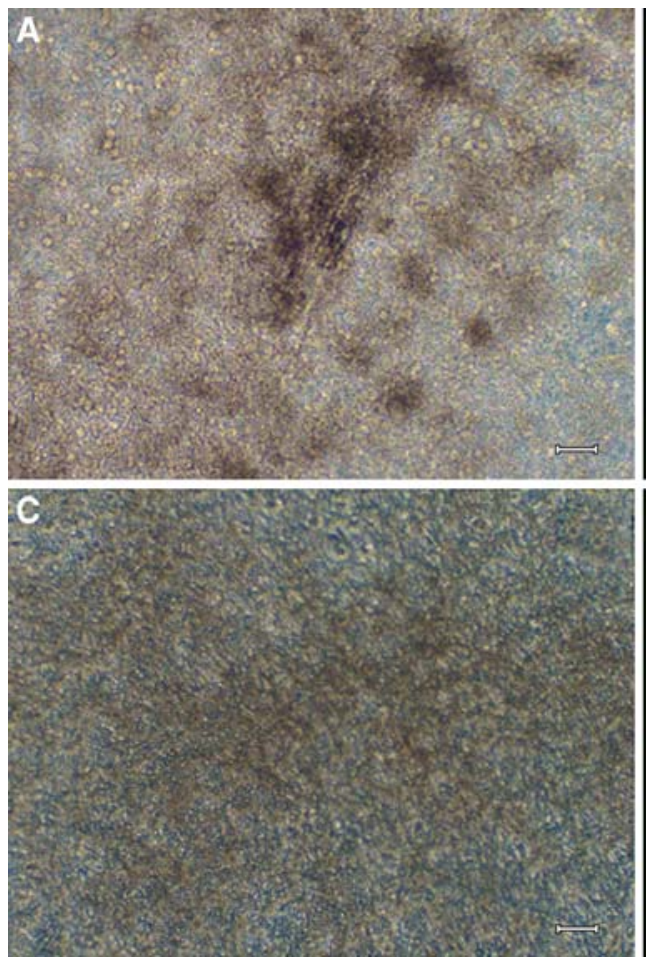

Fig. 2 Binding of fluorescently labeled 6DSS peptide to mineralized bone marrow nodules. MBM cultures were grown and imaged as described in "Materials and Methods." a Bright field image of mineralized mouse bone marrow nodules (MBMNs) from a culture

$\mathrm{CaHPO}_{4}$ concentrations, this was not observed (data not shown). DSS-containing peptides containing C-terminal biotin labels were then synthesized and immobilized on streptavidin-coated beads. The beads were washed and incubated in solutions containing varying concentrations of $\mathrm{CaHPO}_{4}$ as before. Consistent with previous observations for the dentin phosphoproteins/phosphophoryns as well as other phosphoproteins [11, 12], these immobilized peptides caused coaggregation of the beads with particles of amorphous $\mathrm{CaHPO}_{4}$ and eventually led to the deposition of crystalline material around the bead. As illustrated in Fig. 3a, nearly all peptide-coated beads were incorporated into large aggregates of precipitated amorphous calcium phosphate. By comparison, in the biotin-blocked control sample, nearly all beads were unaggregated and unassociated with precipitate (Fig. 3b). Interestingly, several peptide-coated beads became covered with more ordered layers of mineral during the experiment (a representative is shown in Fig. 3c), while all of the uncoated/biotin-blocked control beads failed to accumulate mineral (Fig. 3d).

Tissue-Specific Binding of DSS Peptides to Tooth Surfaces

To test binding of DSS-containing peptides to biological tissue, sagittally sectioned human teeth were incubated

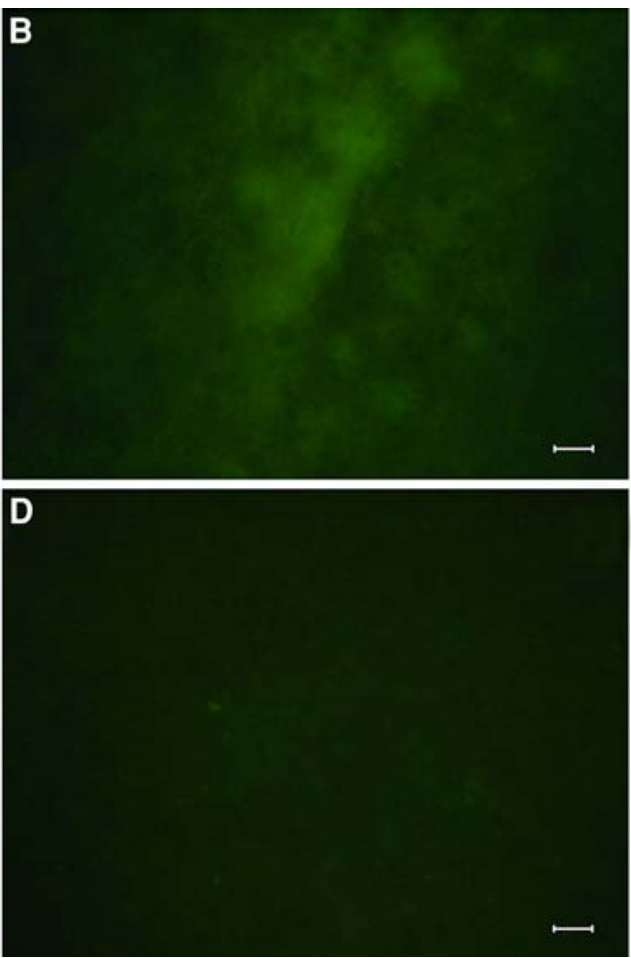

treated with 6DSS. b Fluorescence image of the field shown in a. c Bright field image of mineralized MBMNs from a culture treated with scrambled control peptide. d Fluorescence image of the field shown in c. Bars $=600 \mu \mathrm{m}$

with 6DSS peptide (control samples were prepared without peptide), washed, and imaged by CLSM. Figure 4 shows the intense fluorescent staining of the tooth by the labeled peptide. Mock-treated control sections stained either with scrambled peptide or with free 5(6)-carboxyfluorescein showed no fluorescence (not shown). Interestingly, this peptide specifically binds to the dentin as no binding to the enamel was seen (the leftmost edge of the stained area in Fig. 4 corresponds to the dentin-enamel junction [DEJ]). Examining the spatial pattern of dentin binding by labeled 6DSS (Fig. 4) reveals that staining is brightest in the mantle dentin nearest the DEJ, with noticeably lower levels of staining in the circumpulpal dentin, near the pulp cavity.

\section{DSS-Mediated Remineralization of Tooth Surfaces In Vitro}

Having established that (DSS) $)_{\mathrm{n}}$-containing peptides can bind to the dentin surface and that immobilized peptides could cause the accretion of calcium phosphate, we sought to determine whether these peptides could be used to recruit calcium phosphate to the dentin surface. Demineralized sections of extracted human teeth were treated with 8DSS peptide and then subjected to remineralization with Quell Desensitizer (Pentron Technologies), a commercially available remineralization product consisting of aqueous 

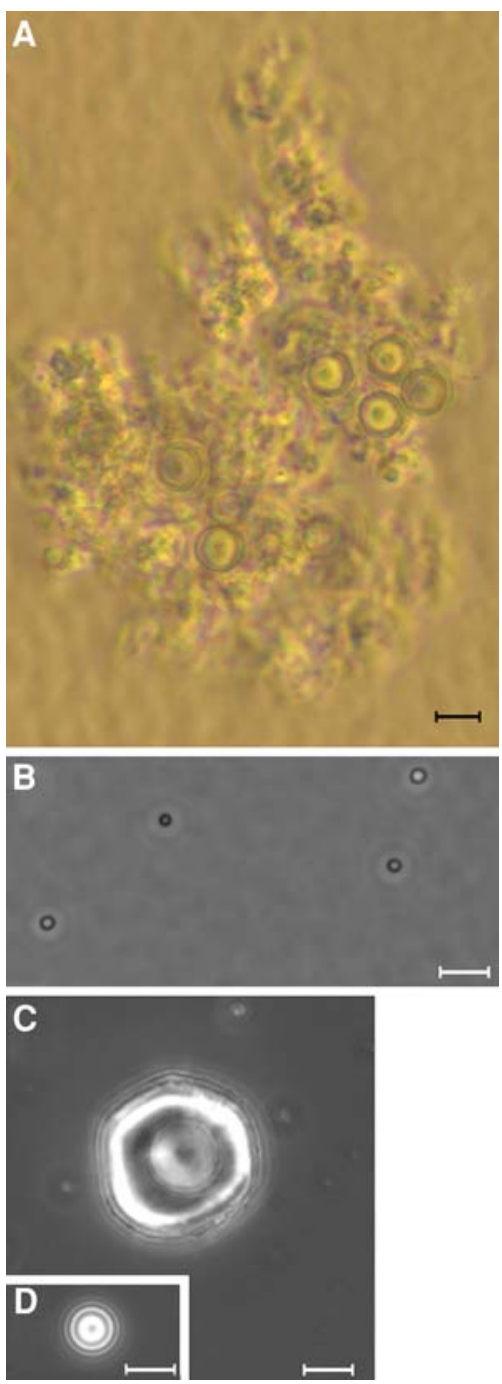

Fig. 3 Interaction of immobilized 8DSS peptide with $\mathrm{CaHPO}_{4}$. Streptavidin-coated polystyrene beads ( $4 \mu \mathrm{m}$ average diameter) were incubated with either biotin-conjugated 8DSS peptide $(\mathbf{a}, \mathbf{c})$ or unconjugated biotin $(\mathbf{b}, \mathbf{d})$. a Bright field micrographs of amorphous calcium phosphate aggregates accumulated around DSS-coated beads. Bar $=4 \mu \mathrm{m}$. b Bright field image of representative biotinblocked beads (no DSS peptide). Bar $=12 \mu \mathrm{m}$. c Phase-contrast micrograph of a DSS-coated bead with a more ordered accretion of calcium phosphate around its exterior. Bar $=4 \mu \mathrm{m}$. d Control sample (biotin-blocked, no DSS peptide). Bar $=4 \mu \mathrm{m}$

solutions of calcium chloride and potassium phosphate. As shown in the electron micrographs in Fig. 5, mock-treated (Fig. 5c) and untreated samples (treated with desensitizer only, Fig. 5d) showed low levels of mineral accumulation, with several dentinal tubules remaining exposed. In contrast, DSS-treated dentin samples (Fig. 5b) accumulated a continuous layer of calcium phosphate precipitate in the presence of desensitizer solution, fully occluding the dentinal tubules.

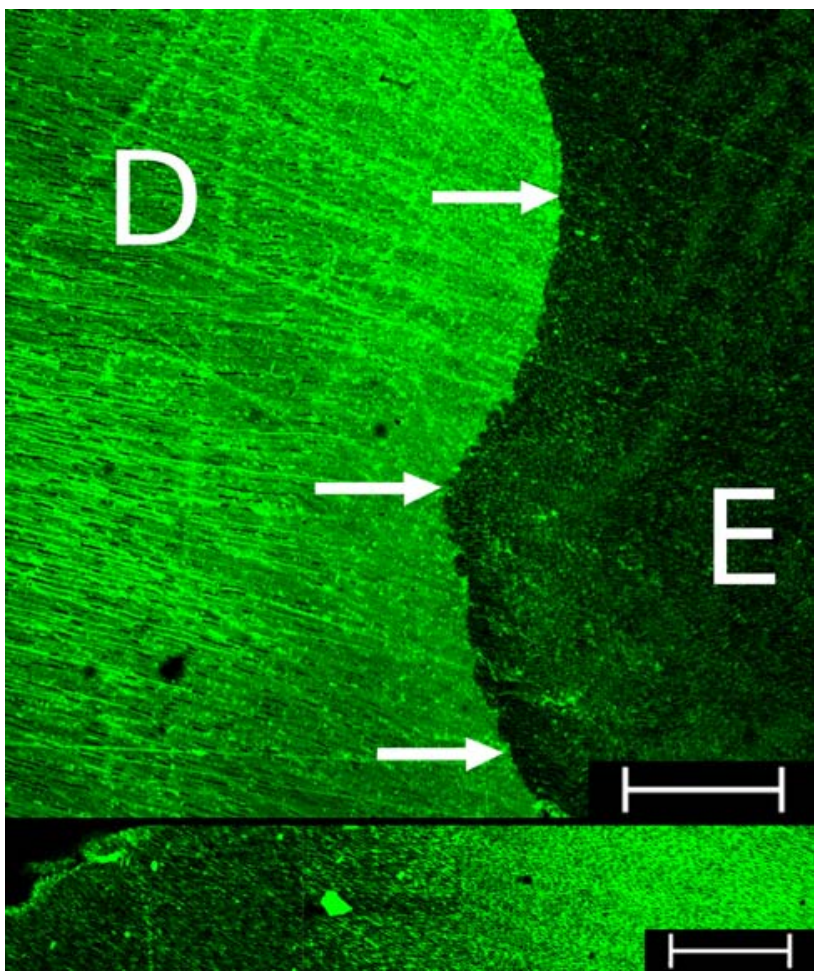

Fig. 4 Binding of labeled DSS to dentin in human teeth. Top Confocal image of fluorescently labeled (DSS) 8 peptide to a sectioned human tooth, showing the enamel $(E)$ and the dentin $(D)$. Arrows indicate the DEJ. Bottom Confocal image of the same tooth, in the region between the mantle dentin (right) and the pulp cavity (left), showing preference of this peptide for mantle dentin over circumpulpal dentin and enamel. Bars $=50 \mu \mathrm{m}$

\section{Discussion}

Biomineralization is one of the central processes in vertebrate development and evolution [18] and references within, affecting processes as diverse as feeding, locomotion, predator avoidance, hearing, and balance. Defects in mineralization or mineralized tissue proteins are involved in human maladies ranging from hereditary deafness [19] and atherosclerosis [20] to dental caries and osteoporosis. Proteins that mediate the mineralization process offer us a template for understanding how to manipulate the deposition of calcium compounds and thus potentially enhance the treatment of calcified tissue defects.

The ubiquitous presence of DPP at sites of calcium phosphate deposition in mammals suggests that this protein plays a direct role in the mineralization process $[1,5-8]$. Biochemical studies have shown that DPP can indeed affect the formation of biologically relevant HA crystals by causing nucleation (at low concentrations) or inhibition (at high concentrations) of crystal growth [4, 12]. Proteins involved in mineralization processes in vertebrates (including DPP) often contain negatively charged, Asp- or 
Fig. 5 Scanning electron micrographs of sagittal tooth sections, treated as indicated: a untreated control; b pretreated with 8DSS for $1 \mathrm{~h}$, rinsed, and remineralized using Quell desensitizer; c preincubated with buffer (50 mM HEPES, $\mathrm{pH}$ 7.0), followed by remineralization as in $\mathbf{b}$; $\mathbf{d}$ no preincubation, remineralization as in $\mathbf{b}$. Bars $=50 \mu \mathrm{m}$
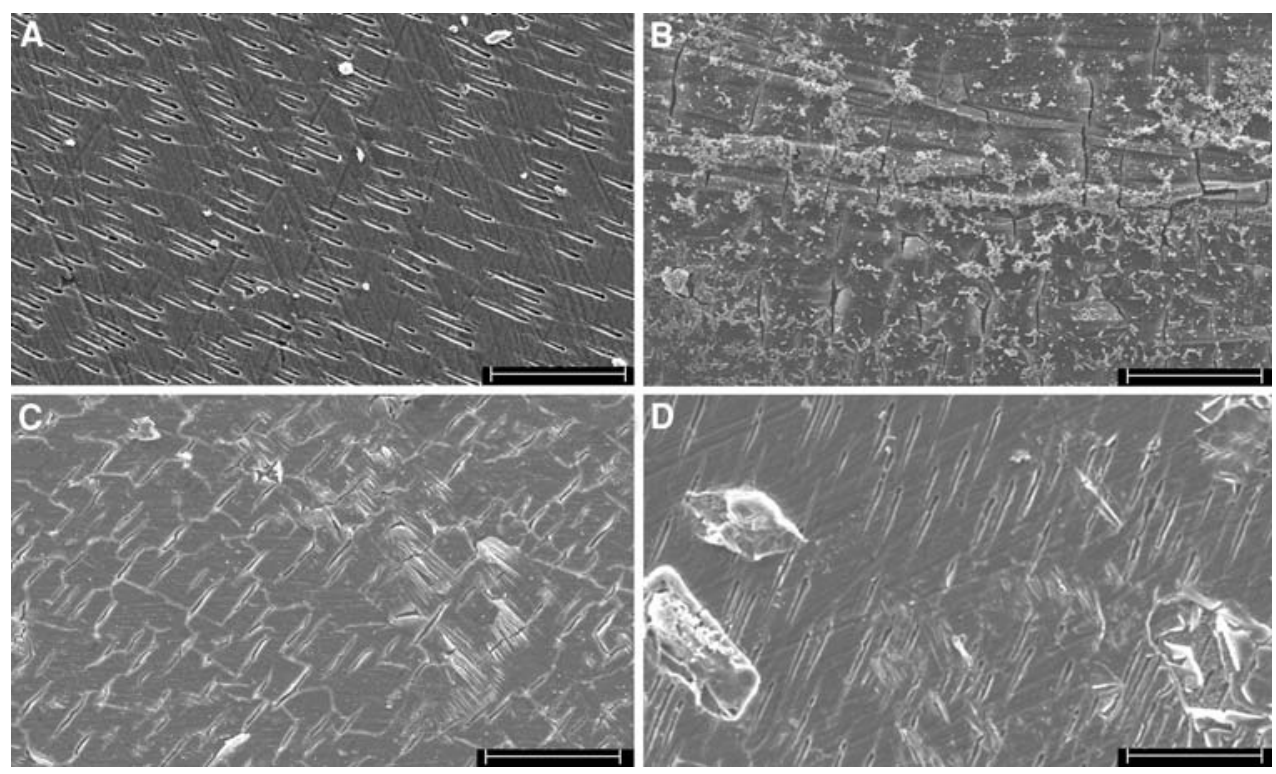

Glu-rich domains ([21], and references within). This observation combined with computational and biochemical studies of the (DSS) $)_{n}$ repeat region $[2,3,13,15]$ indicated that this short repeated sequence governs the mineral binding and nucleation activity of DPP.

Given the known dependence of DPP activity on its phosphorylation state [11,22], it was not surprising that unphosphorylated DSS-containing peptides failed to nucleate HA formation in free solution. However, we found that even in the absence of phosphorylation, these peptides bound tightly and specifically to calcium phosphate compounds, suggesting that the (DSS) $)_{n}$ motif itself may be useful in identifying, illuminating, and manipulating calcified surfaces.

In characterizing the behavior of these molecules, it was found that the binding affinities measured for the DSS peptides compare favorably with affinities measured for other known HA-binding proteins and peptides. For example, the HA binding affinity of the 8DSS peptide $\left(290,000 \mathrm{M}^{-1}\right)$, which consists of 24 amino acids, is only sevenfold less than that of fully assembled amelogenin nanospheres $\left(1,970,000 \mathrm{M}^{-1}\right)$ [23], which consist of up to 40 individual $\sim 25-\mathrm{kDa}$ subunits. Additionally, the C-terminal region of amelogenin is reported to have an HA-binding affinity of $6,200 \mathrm{M}^{-1}$ [24], while in contrast, the similarly sized 4DSS peptide has an affinity of $94,000 \mathrm{M}^{-1}$. The binding affinity of 8DSS compares favorably with measured values for the comparably sized histatins $\left(\mathrm{K}=353,000-1,903,000 \mathrm{M}^{-1}\right.$ [25]), a class of small antimicrobial peptides that are known to bind HA with high affinity.

Binding of DSS-containing peptides to defined HA substrates depends strongly on the length of the peptides, with the affinity increasing in proportion to peptide size up to a length of six repeats (18 amino acids), with little additional increase in affinity seen in peptides with eight repeats (Table 1). Six repeats thus appears to be optimal for interaction with HA surfaces, possibly reflecting the maximum number of functional groups from the peptide that can effectively interact with the surface at a given time. On the other end of the length scale, the 2DSS peptide, containing only two repeats of the DSS sequence, shows an HA binding affinity much lower than that of the longer variants $\left(57,000 \mathrm{M}^{-1}\right)$ but well above values observed for the binding of individual amino acids $\left(5,000-13,200 \mathrm{M}^{-1}\right.$ for phosphoserine [26, 27], $220 \mathrm{M}^{-1}$ for Asp [26], $206 \mathrm{M}^{-1}$ for glutamic acid [28]).

Peptide binding to HA surfaces also depended on their sequence, with nearly all variant peptides showing significant reductions in binding affinity relative to the parent DSS sequence (Table 1, Fig. 1b, c). Our results show that the primary sequence determinant of binding is a negative charge at position 1 of the repeat. This is perhaps not surprising, considering that studies of extremely large polymers of aspartic acid show a very high HA binding affinity (3,000,000 $\mathrm{M}^{-1}$ for a 28.8-kDa polymer [29]). Substitutions of the serines in the DSS repeat also lead to reductions in binding activity, albeit much less severely. In the past, measurements of the binding affinity of serine to HA have ranged from those too low to subject to Langmuir analysis [27] to much higher values $\left(317,000 \mathrm{M}^{-1}\right.$ but with a very small number of binding sites per meter squared of HA [26]) depending on the specific HA preparation used, suggesting the possibility of a complex and possibly highly specific interaction between serine and discrete regions of HA surfaces. Our initial experiments indicate that binding of DSScontaining peptides to HA results primarily from the contributions of the aspartic acid residues, with the serines playing a smaller but still significant role. 
Binding of (DSS $)_{\mathrm{n}}$-containing peptides to defined HA surfaces in vitro led us to investigate the binding of these peptides to calcified biological tissues. Fluorescein-labeled 8DSS peptide binds tightly to the dentin of extracted adult human molars with remarkable tissue specificity, binding primarily to the mantle dentin, with binding to the enamel almost completely absent. It should be noted that the HA crystals of the dentin show very different morphologies from those of the enamel, consisting of smaller, platelike crystals with essentially random orientations, rather than the elongated, well-oriented HA crystals of the enamel surface [10, 30]. Thus, it is possible that the binding specificity of (DSS) n $^{-}$ containing peptides to regions of the dentin may be due to selective binding of this specific HA crystal form or (especially in light of the observed binding to amorphous calcium phosphates) may reflect a simple preference of these peptides for less ordered surfaces. Binding was also observed to mineralizing mouse bone marrow nodules, further indicating that these peptides may be useful in identifying and manipulating a wide variety of mineralized tissues.

Though the unphosphorylated DSS-containing peptides examined in this study failed to nucleate HA formation in free solution, they were able to effectively bind amorphous calcium phosphate aggregates. By immobilizing these peptides on a solid support, we were able to harness this ability as a means of controlling the site of calcium phosphate deposition in saturated solutions. Polystyrene beads with 8DSS peptide immobilized on their surfaces were found to effectively aggregate amorphous calcium phosphate from saturated $\mathrm{CaHPO}_{4}$ solutions. Upon further incubation, however, single beads were found to accrete layers of more ordered, crystalline calcium phosphate, even without phosphorylation of the peptides. This unexpected behavior marks a departure from what has been observed for the DPP protein and suggests that the full-length protein likely contains additional regulatory mechanisms to help govern HA nucleation. This result also suggests that the (DSS) ${ }_{\mathrm{n}}$-containing peptides can be enormously versatile in manipulating the deposition of calcium phosphate.

Our investigations of the ability of (DSS) ${ }_{\mathrm{n}}$-containing peptides to initiate mineral deposition on tooth surfaces revealed that pretreatment with 8 DSS peptide markedly enhanced the effectiveness of a commercially available remineralization product in causing the aggregation of mineral at the surface of partially demineralized dentin. Molecular dynamics simulations using theoretical Asp/Ser and Asp/phosphoserine-rich peptides have shown that these peptides likely adopt extended conformations, presenting functional groups on either side of a plane parallel to the interaction surface [13, 31; D. K. Y. and W. S., unpublished]. In the specific case of peptides based on the Asp-Ser-Ser repeat, this has the effect of providing two equivalent mineral binding faces, allowing surface-immobilized peptides to actively bind passing amorphous calcium phosphate particles, thus leading to the observed increase in amorphous calcium phosphate accumulation on 8DSS-pretreated HA surfaces. This activity presents these peptides as promising alternatives for enhancing tooth remineralization.

The ability to specifically bind to calcified surfaces and to recruit calcium phosphate offers many other unique opportunities for diagnostic and therapeutic interventions. While these activities resided in large proteins, it was not practical to contemplate their use in clinical applications; but the present demonstration of similar behavior by readily synthesized small peptides provides the possibility of powerful new tools to diagnose and treat disorders of calcified tissues. We have already presented the example of enhancing the effectiveness of existing remineralization regimens by pretreatment of surfaces with (DSS) $)_{n}$-containing peptides, and many other possibilities remain to be explored. Current methods of diagnosing dental caries, e.g., rely on manual probing, colorimetric staining, or laser-based fluorimetry or interferometry to identify the sites of carious lesions $[32,33]$. Given the affinity of the (DSS) $)_{n}$ peptides for amorphous calcium phosphate and their lack of binding to healthy enamel, fluorescently labeled (DSS) ${ }_{n}$ peptides could possibly be used to rapidly identify carious and pre-carious lesions in teeth. This method would have far greater precision than colorimetric dyes (reliance on which can lead to the removal of healthy enamel [34]) and improved sensitivity compared to radiography or fluorescence-based methods that rely on native tissue fluorescence.

Because (DSS) $)_{\mathrm{n}}$-containing peptides can readily be attached to any number of labels or accessory compounds, their usefulness in diagnostic applications is limited only by the range of their tissue specificity. We have made extensive use of fluorescently labeled peptides in this study, but it is also possible to attach iodinated compounds for use as radiographic contrast agents [35] as well as spin-labeled tags to enhance contrast in magnetic resonance imaging. Yokogawa et al. [36] showed that it was possible to target estradiol to calcified tissues by attaching it to short chains of polyaspartate. Similarly, it is possible to attach therapeutic compounds, such as antimicrobials or growth factors, to $(\mathrm{DSS})_{\mathrm{n}}$-containing peptides in order to target their delivery to specific calcified surfaces with even greater precision.

Currently, efforts are under way to identify the range of tissue specificity of these peptides and to engineer variants with expanded or narrowed specificity that will allow us to take advantage of their mineral binding activity in more precise ways. The DPP is composed in large part of (DSS) repeats and exerts powerful effects on the rate and type of mineralization in developing teeth [10]: By applying the tools of peptide engineering to DPP-derived (DSS) ${ }_{\mathrm{n}}$-like peptides, we hope to unlock the full potential of this unique mineral-binding motif. 
Open Access This article is distributed under the terms of the Creative Commons Attribution Noncommercial License which permits any noncommercial use, distribution, and reproduction in any medium, provided the original author(s) and source are credited.

\section{References}

1. Hao J, Zou B, Narayanan K, George A (2004) Differential expression patterns of the dentin matrix proteins during mineralized tissue formation. Bone 34:921-932

2. Veis A, Wei K, Sfeir C, George A, Malone J (1998) Properties of the (DSS) $)_{n}$ triplet repeat domain of rat dentin phosphophoryn. Eur J Oral Sci 106(Suppl 1):234-238

3. Lee SL, Veis A (1980) Cooperativity in calcium ion binding to repetitive, carboxylate-serylphosphate polypeptides and the relationship of this property to dentin mineralization. Int J Pept Protein Res 16:231-240

4. Lussi A, Crenshaw MA, Linde A (1988) Induction and inhibition of hydroxyapatite formation by rat dentine phosphoprotein in vitro. Arch Oral Biol 33:685-691

5. Rahima M, Tsay TG, Andujar M, Veis A (1988) Localization of phosphophoryn in rat incisor dentin using immunocytochemical techniques. J Histochem Cytochem 36:153-157

6. Begue-Kirn C, Krebsbach PH, Bartlett JD, Butler WT (1998) Dentin sialoprotein, dentin phosphoprotein, enamelysin and ameloblastin: tooth-specific molecules that are distinctively expressed during murine dental differentiation. Eur J Oral Sci 106:963-970

7. Bleicher F, Couble ML, Farges JC, Couble P, Magloire H (1999) Sequential expression of matrix protein genes in developing rat teeth. Matrix Biol 18:133-143

8. Baba O, Qin C, Brunn JC, Jones JE, Wygant JN, McIntyre BW, Butler WT (2004) Detection of dentin sialoprotein in rat periodontium. Eur J Oral Sci 112:163-170

9. Boskey A, Spevak L, Tan M, Doty SB, Butler WT (2000) Dentin sialoprotein (DSP) has limited effects on in vitro apatite formation and growth. Calcif Tissue Int 67:472-478

10. Paine ML, Luo W, Wang HJ, Bringas P Jr, Ngan AY, Miklus VG, Zhu DH, MacDougall M, White SN, Snead ML (2005) Dentin sialoprotein and dentin phosphoprotein overexpression during amelogenesis. J Biol Chem 280:31991-31998

11. Saito T, Arsenault AL, Yamauchi M, Kuboki Y, Crenshaw MA (1997) Mineral induction by immobilized phosphoproteins. Bone 21:305-311

12. Saito T, Yamauchi M, Abiko Y, Matsuda K, Crenshaw MA (2000) In vitro apatite induction by phosphophoryn immobilized on modified collagen fibrils. J Bone Miner Res 15:1615-1619

13. George A, Bannon L, Sabsay B, Dillon JW, Malone J, Veis A, Jenkins NA, Gilbert DJ, Copeland NG (1996) The carboxyl-terminal domain of phosphophoryn contains unique extended triplet amino acid repeat sequences forming ordered carboxyl-phosphate interaction ridges that may be essential in the biomineralization process. J Biol Chem 271:32869-32873

14. Cross KJ, Huq NL, Reynolds EC (2005) Protein dynamics of bovine dentin phosphophoryn. J Pept Res 66:59-67

15. Chang S, Chen H, Liu J, Wood D, Bentley P, Clarkson B (2006) Synthesis of a potentially bioactive, hydroxyapatite-nucleating molecule. Calcif Tissue Int 78:55-61

16. Calis S, Jeyanthi R, Tsai T, Mehta RC, DeLuca PP (1995) Adsorption of salmon calcitonin to PLGA microspheres. Pharm Res 12:1072-1076

17. Atkins PW (1994) Physical chemistry. Freeman, New York

18. Kawasaki K, Suzuki T, Weiss KM (2004) Genetic basis for the evolution of vertebrate mineralized tissue. Proc Natl Acad Sci USA 101:11356-11361
19. Xiao S, Yu C, Chou X, Yuan W, Wang Y, Bu L, Fu G, Qian M, Yang J, Shi Y, Hu L, Han B, Wang Z, Huang W, Liu J, Chen Z, Zhao G, Kong X (2001) Dentinogenesis imperfecta 1 with or without progressive hearing loss is associated with distinct mutations in DSPP. Nat Genet 27:201-204

20. Magne D, Julien M, Vinatier C, Merhi-Soussi F, Weiss P, Guicheux J (2005) Cartilage formation in growth plate and arteries: from physiology to pathology. Bioessays 27:708-716

21. Harris NL, Rattray KR, Tye CE, Underhill TM, Somerman MJ, D'Errico JA, Chambers AF, Hunter GK, Goldberg HA (2000) Functional analysis of bone sialoprotein: identification of the hydroxyapatite-nucleating and cell-binding domains by recombinant peptide expression and site-directed mutagenesis. Bone 27:795-802

22. He G, Ramachandran A, Dahl T, George S, Schultz D, Cookson D, Veis A, George A (2005) Phosphorylation of phosphophoryn is crucial for its function as a mediator of biomineralization. $\mathrm{J}$ Biol Chem 280:33109-33114

23. Bouropoulos N, Moradian-Oldak J (2003) Analysis of hydroxyapatite surface coverage by amelogenin nanospheres following the Langmuir model for protein adsorption. Calcif Tissue Int 72:599-603

24. Aoba T, Moreno EC, Kresak M, Tanabe T (1989) Possible roles of partial sequences at $\mathrm{N}$ - and $\mathrm{C}$-termini of amelogenin in protein-enamel mineral interaction. J Dent Res 68:1331-1336

25. Yin A, Margolis HC, Grogan J, Yao Y, Troxler RF, Oppenheim FG (2003) Physical parameters of hydroxyapatite adsorption and effect on candidacidal activity of histatins. Arch Oral Biol 48:361-368

26. Moreno EC, Kresak M, Hay DI (1984) Adsorption of molecules of biological interest onto hydroxyapatite. Calcif Tissue Int 36:48-59

27. Benaziz L, Barroug A, Legrouri A, Rey C, Lebugle A (2001) Adsorption of O-phospho-L-serine and L-serine onto poorly crystalline apatite. J Colloid Interface Sci 238:48-53

28. Kresak M, Moreno EC, Zahradnik RT, Hay DI (1977) Adsorption of amino acids onto hydroxyapatite. J Colloid Interface Sci 59:283-292

29. Tsortos A, Nancollas GH (1999) The adsorption of polyelectrolytes on hydroxyapatite crystals. J Colloid Interface Sci 209:109115

30. Bath-Balogh M, Fehrenbach MJ (2006) Dental embryology, histology, and anatomy. Elsevier Saunders, St. Louis

31. Dahlin S, Angstrom J, Linde A (1998) Dentin phosphoprotein sequence motifs and molecular modeling: conformational adaptations to mineral crystals. Eur J Oral Sci 106(Suppl 1):239-248

32. Audette GF, Irvin RT, Hazes B (2004) Crystallographic analysis of the Pseudomonas aeruginosa strain K122-4 monomeric pilin reveals a conserved receptor-binding architecture. Biochemistry 43:11427-11435

33. Tranaeus S, Shi XQ, Angmar-Mansson B (2005) Caries risk assessment: methods available to clinicians for caries detection. Community Dent Oral Epidemiol 33:265-273

34. Yip HK, Stevenson AG, Beeley JA (1994) The specificity of caries detector dyes in cavity preparation. Br Dent J 176:417-421

35. Lee TC, Mohsin S, Taylor D, Parkesh R, Gunnlaugsson T, O'Brien FJ, Giehl M, Gowin W (2003) Detecting microdamage in bone. J Anat 203:161-172

36. Yokogawa K, Miya K, Sekido T, Higashi Y, Nomura M, Fujisawa R, Morito K, Masamune Y, Waki Y, Kasugai S, Miyamoto K (2001) Selective delivery of estradiol to bone by aspartic acid oligopeptide and its effects on ovariectomized mice. Endocrinology 142:1228-1233 